\title{
研究水利调度中自动化系统的应用
}

\author{
魏晓 \\ 新疆伊犁河流域开发建设管理局 \\ DOI:10.32629/hwr.v4i8.3252
}

\begin{abstract}
[摘 要] 在我国国民经济和社会的不断发展过程中,水利工程已经成为了我国的基础产业之一。但是水 利工程的建设周期长而且消耗的人力、物力资源也比较大, 对自然环境、地形地质以及气候的要求比较 严格。为了顺应时代的发展,水利工程在建设的过程中应该遵循国家的建设政策,满足国家对建设技术的 标准。本文通过对水利工程调度进行分析,并了解自动化系统在水利调度中的应用现状。
\end{abstract}

[关键词] 水利工程; 水利调度; 自动化系统

中图分类号：TV747 文献标识码：A

水利工程关系着国家经济的发展和 民生的改善问题, 在现代技术的发展状 态下, 将信息化、自动化广泛应用在工程 建筑中, 能有效提高工程建设的效率和 质量。自动化技术以及网络技术的应用 能够形成一个将控制、运行以及管理融 为一体的管理模式, 有效促进当前经济 的增长。

\section{1 水利调度}

水利工程具有蓄水、排水、挡水的 功用, 然后按照水利需求, 对江河水流的 时间和空间进行合理的分配或者江河湖 泊的水位进行调节, 这个过程就叫做水 利调度 ${ }^{[1-2]}$ 。

\section{1 水利调度的原因}

水利调度是为了满足国民经济的发 展需求, 对江河湖泊的流径和水位进行 时间和空间上的合理分配。水利调度就 是在确保水利工程安全的前提下, 满足 除害兴利以及水资源的充分利用等要 求。水利调度可以按照效益或者工程来 进行分类, 按照效益可分为防洪调度、兴 利调度; 按照工程可分为水库调度或者 水闸调度。水库在水利中属于主导位置, 所以在水利调度中, 水库调度至关重要。

\section{2 水利调度的目的}

水利工程的建设不仅要符合各部门 的要求, 同时还要保证水利工程的安全 和质量。水利工程的调度要根据系统实 际的组成情况以及水利要达到的任务标
准, 对相关的调度原则和控制指标进行 合理的修改, 并通过水情的汇报情况进 行实时的调度。在防洪方面, 水利调度能 够安全堤防度汛, 减少分洪蓄洪的损失; 在灌溉方面, 水利调度能使灌溉系统的 供水效率达到应有的标准, 即是在遇到 长期干旱的情况也能减少水分的流失; 在水利发电方面, 能够保证水电站群对 电力系统的供电效率达到标准, 实现最 大发电量。明确水利调度所要完成的功 能分配和相互结合的情况, 维护好防洪 和兴利的关系、各兴利部门之间的关系、 水量和泥沙调节的关系, 以此来实现水 利系统调度的综合应用, 以整体的效益 为标准来进行统一的调度。

1.3 水利调度原则

水利调度的首要目标就是保证工程 建设的安全, 从工程的整体效益出发, 实 现水资源的充分利用, 同时还要根据工 程的任务分配以及系统组成的实际情况, 制定合理的工程调度原则。

防洪系统的调度原则, 该系统主要 是以河道堤防和水库组成为主, 根据河 道的防洪能力以及水库的水流量、下游 区遭遇的洪水等实际情况来控制水库的 泄水量, 并进行适当的调节, 充分发挥防 洪的作用。如果该系统中有分洪工程的 配合, 那么当水库的蓄水量达到一定程 度或者蓄满的情况下, 需要根据洪水的 实际情况, 选择合理的工作方案, 降低洪
水带来的损失。

水利灌溉系统的调度原则, 水利灌 溉多以农田为主, 根据农田的分部情况, 对工程的灌溉范围进行合理的划分, 然 后由水库库内进行引水和提水或直接 由河道引水灌溉, 同时还要将骨干水库 以及灌溉附近的堰塘河道合理应用起 来。一般情况下, 骨干水库的调节性能 较高, 所以可以先用小水库和堰塘进行 存水, 然后由骨干水库进行补充。但是 在用水的高峰季节, 应该尽量保证水库 和堰塘的水是满的, 从而加大供水量。 如果骨干水库的调节性能较差, 水量过 多时, 可以先用骨干水库进行供水, 其 他小水库和堰塘用来存水。也可以充分 利用该区域内的渠灌和井灌来提高区 域内灌溉的效率。

水力发电系统的调度原则, 前提是 必须满足电力系统的要求, 然后合理运 用水电站。一般的调度原则, 例如径流式 水电站, 它是根据出水量来决定调节力 度的, 再满足系统要求的前提下进行补 偿调度。当电力系统需要的调峰容量不 足时, 就需要抽水蓄能电站进行多余电 力的抽水蓄能, 在日负荷处于高峰时进 行发电来满足系统的需求。

水利系统调度原则的综合应用, 在 防洪、供水、发电、灌溉渔业等领域都 有很重要的作用。将承担的任务和应用 的主次关系充分结合起来, 制定出合理 
的调度原则, 维护好防洪兴利以及各部 门之间的关系, 充分发挥出水利调度的 作用。

\section{2 自动化系统在水利调度应用} 中存在的问题

\section{1 资金投入不足}

信息自动化处理技术虽然能有效保 障施工的质量, 但是这项技术的研究和 应用难度也非常大, 对资金的消耗和技 术的要求更高。而在实际的水利工程建 设施工过程中, 一些相关的建筑单位, 为 了保证工程进度和经济收益, 在自动化 管理上投入的资金是有限的, 对水利工 程的信息化管理水平和工程建设都有直 接的影响 ${ }^{[3]}$ 。

\section{2 信息自动化水平低}

施工人员是整个工程建设的主体, 在信息自动化管理和操作中都有非常重 要的作用。虽然目前的信息自动化技术 使大部分的工作人员得到了解放, 但是 技术的操作是不能完全离开人工管理 的。由于企业的资金投入有限, 在实际的 水利水电工程建设过程中没有专业性的 信息自动化技术操控人员, 这样对实际 的工程建设以及资金的节省都有很大的 影响。

\section{3 自动化系统应用问题的解决}

\section{措施}

3. 1提高技术的使用, 引进高素质 人才

要想充分发挥出信息自动化技术在 水利调度中的作用, 就必须让每个施工 人员及管理人员从根本意识上加强对信
息自动化技术的应用, 并结合实际的水 利水电工程建设进行合理的资金投入。 水利工程建设对经济的发展有非常重要 的作用, 而信息自动化技术可以有效解 决在建设过程中资料的收集和整理问题, 对建设要求、施工材料进行详细的掌握, 制定出合理的水利调度方案, 保证工程 建设的高效性、可靠性。

3.2 建立完善的操作管理制度

有效的管理制度, 能够更好的保证 水利水电工程的建设。这样员工在进行 工作的过程中有了严格的制度要求, 同 时也方便管理者对员工的监督。水利调 度工作中, 建立完善的管理制度, 能够促 使工作人员严格的根据信息自动化技术 的操作流程来开展工作。工作人员有序 的进行工作, 保证了工作效率的同时也 将自动化技术的应用发挥到了极致。水 利水电作为我国的基础行业之一, 对国 家经济的发展有很重要的作用。在现在 的广泛应用中利用信息自动化管理技术 来提高工程质量和效率, 对水利水电工 程的发展是非常有必要的。

3. 3结合实际情况对项目进行研究

充分了解水利工程的建设现状, 保 证水利工程的管理工作更加具有科学性 和可行性。同时还要对工程进行严格的 篮选, 特别是那些社会效益、经济效益不 满足要求或者与当地发展现状不符的要 进行驳回。对于那些重点的水利工程要 求更高, 要在满足上述条件的前提下, 再 成立一个专门的检查小组对实际的工程 建设地点进行勘察, 然后再进行评审, 避
免建设过程中出现隐瞒、谎报等不良现 象。同时还要对当地居民的想法进行了 解, 必须遵循他们的意见才能对工程进 行立项、审批以及施工。

3. 4 建立施工质量管理体系

该项体系主要是以现场施工建设管 理组织机构为主, 然后结合质量管理制 度来进行建立。施工质量管理体系按照 施工管理范围可以划分为现场施工管理 目标体系、质量管理组织和控制体系以 及质量管理沟通协调体系等等。在施工 之前, 制定一套合理的施工管理制度和 流程, 确定下施工的程序和方式, 同时对 技术和经济要做好详细的管理措施, 便 于水利工程的顺利进行。

\section{4 结语}

目前, 我国已经建成了很多大型且 有效的水利系统, 对防洪、灌溉、供水等 都有显著的作用。但是信息自动化技术 在水利调度中的应用还存在一些问题, 发展还不平衡, 一些先进的技术还需要 加强推广和应用, 在实践的过程中将水 利调度工作做到最优化、自动化。

\section{[参考文献]}

[1]付振飞.水利调度中自动化系统 的应用 [J]. 环球市场信息导报（理 论),2015(01):70-71.

[2]薛井俊,王德俊,霍安新.江都水 利枢纽调度中心自动化系统的研究 [J]. 水利信息化,2011(03):64-67+72.

[3]董文全,张放.可靠性设计在水利 调度自动化系统中的研究[J].黑龙江科 技信息,2014(12):61. 